\title{
Differential brain activation patterns in adult attention- deficit hyperactivity disorder (ADHD) associated with task switching
}

Citation for published version (APA):

Dibbets, P., Evers, E. A. T., Hurks, P. P. M., Bakker, K., \& Jolles, J. (2010). Differential brain activation patterns in adult attention-deficit hyperactivity disorder (ADHD) associated with task switching. Neuropsychology, 24(4), 413-423. https://doi.org/10.1037/a0018997

Document status and date:

Published: 01/07/2010

DOI:

10.1037/a0018997

Document Version:

Publisher's PDF, also known as Version of record

Document license:

Taverne

Please check the document version of this publication:

- A submitted manuscript is the version of the article upon submission and before peer-review. There can be important differences between the submitted version and the official published version of record.

People interested in the research are advised to contact the author for the final version of the publication, or visit the DOI to the publisher's website.

- The final author version and the galley proof are versions of the publication after peer review.

- The final published version features the final layout of the paper including the volume, issue and page numbers.

Link to publication

\footnotetext{
General rights rights.

- You may freely distribute the URL identifying the publication in the public portal. please follow below link for the End User Agreement:

www.umlib.nl/taverne-license

Take down policy

If you believe that this document breaches copyright please contact us at:

repository@maastrichtuniversity.nl

providing details and we will investigate your claim.
}

Copyright and moral rights for the publications made accessible in the public portal are retained by the authors and/or other copyright owners and it is a condition of accessing publications that users recognise and abide by the legal requirements associated with these

- Users may download and print one copy of any publication from the public portal for the purpose of private study or research.

- You may not further distribute the material or use it for any profit-making activity or commercial gain

If the publication is distributed under the terms of Article $25 \mathrm{fa}$ of the Dutch Copyright Act, indicated by the "Taverne" license above, 
See discussions, stats, and author profiles for this publication at: https://www.researchgate.net/publication/45095632

\section{Differential Brain Activation Patterns in Adult Attention-Deficit Hyperactivity Disorder (ADHD) Associated With Task Switching}

Article in Neuropsychology · July 2010

DOI: 10.1037/a0018997 · Source: PubMed

CITATIONS

58

5 authors, including:

Pauline Dibbets

Maastricht University

44 PUBLICATIONS 616 CITATIONS

SEE PROFILE

Jelle Jolles

Vrije Universiteit Amsterdam

723 PUBLICATIONS 38,916 CITATIONS

SEE PROFILE

Some of the authors of this publication are also working on these related projects:

Project SMART MOVES! View project

Causes and consequences of cerebral white matter lesions View project
READS

462

Petra P M Hurks

Maastricht University

56 PUBLICATIONS 1,581 CITATIONS

SEE PROFILE 


\title{
Differential Brain Activation Patterns in Adult Attention-Deficit Hyperactivity Disorder (ADHD) Associated With Task Switching
}

\author{
Pauline Dibbets, Elisabeth A. T. Evers, \\ Petra P. M. Hurks, and Katja Bakker \\ Maastricht University
}

\author{
Jelle Jolles \\ VU University Amsterdam
}

\begin{abstract}
Objective: The main aim of the study was to examine blood oxygen level-dependent response during task switching in adults with attention-deficit/hyperactivity disorder (ADHD). Method: Fifteen male adults with ADHD and 14 controls participated and performed a task-switching paradigm. Results: Behaviorally, no specific executive control problems were observed in the ADHD participants, although they did display more errors in general. The neuroimaging data did show remarkable differences between the ADHD and control adults: Adults with ADHD engaged more strongly the dorsal anterior cingulate cortex, middle temporal gyrus, precuneus, lingual gyrus, precentral gyrus, and insula than did the healthy controls during task switching. Controls displayed more task-related activity in the putamen, posterior cingulate gyrus, medial frontal gyrus, thalamus, orbitofrontal cortex, and postcentral gyrus. Conclusions: ADHD adults did not display specific executive control problems at a behavioral level, but did engage different brain areas during task switching compared with healthy controls. The results are discussed in the framework of the executive frontostriatal circuitry, conflict detection, and attentional networks.
\end{abstract}

Keywords: attention-deficit/hyperactivity disorder, executive control, task switching, neuroimaging, frontostriatal circuitry

Attention-deficit/hyperactivity disorder (ADHD) is a developmental disorder that is characterized by a pattern of chronic symptoms, including attention problems, hyperactivity, and impulsivity (American Psychiatric Association, 1994). Over the past decades, evidence has accumulated that ADHD is not restricted to childhood, but that symptoms of ADHD persist into adulthood at least for $60 \%$ of children diagnosed with ADHD (Barkley, 1996; Spencer, Biederman, \& Mick, 2007). Like children, adults with ADHD encounter highly comparable clinical features, comorbidities, neuropsychological deficits, and failures in major life domains, such as work, academic, and social problems (Biederman, Mick, \& Faraone, 2000; Faraone et al., 2000).

Several studies on ADHD have indicated that not only children but also adults can experience executive control deficits (for an overview, see Seidman, 2006). Executive control is an umbrella term that comprises a collection of interrelated cognitive processes responsible for goal-directed behavior. There are numerous exec-

Pauline Dibbets, Department of Clinical Psychological Science, Faculty of Psychology and Neuroscience, Maastricht University, the Netherlands; Elisabeth A. T. Evers, Petra P. M. Hurks, and Katja Bakker, Department of Neuropsychology and Psychopharmacology, Faculty of Psychology and Neuroscience, Maastricht University, the Netherlands; Jelle Jolles, Department of Special Education, Faculty of Psychology and Education, VU University Amsterdam, Amsterdam, the Netherlands.

We thank Etienne Lemaire and Walter Backes for providing comments and help on the MRI protocol. Further, we thank Dymphie Scholtissen-in de Braek and Natalie Marchetta for the active recruitment and testing of the ADHD participants.

Correspondence concerning this article should be addressed to Pauline Dibbets, Maastricht University, Universiteitssingel 40, Clinical Psychological Science, PO Box 616, 6200 MD Maastricht, the Netherlands. E-mail: Pauline.Dibbets@maastrichtuniversity.nl utive control processes for example, planning, attentional control, mental flexibility, utilization of feedback, working memory, and self-regulation, such as response inhibition or resistance to interference. The deficits in executive control in adult ADHD have been observed in several domains, such as response inhibition (Epstein, Johnson, Varia, \& Conners, 2001; Murphy, 2002b; Ossmann \& Mulligan, 2003), problem solving (Murphy, 2002a), and switching between rules or tasks (Tamm, Menon, Ringel, \& Reiss, 2004; White \& Shah, 2006). Neuroimaging studies suggest that deficits in executive control in children and adolescents with ADHD are associated with aberrant activation in the (pre)frontostriatal circuitry (for reviews, see Bush, Valera, \& Seidman, 2005; Durston, 2003; Tripp \& Wickens, 2009). This circuitry comprises, among other structures, the lateral prefrontal cortex (PFC), putamen, caudate nucleus, and anterior cingulate cortex.

With the increased recognition that ADHD symptoms persist into adulthood, the amount of neuroimaging studies on adult ADHD also steadily increases. Several studies have investigated brain activation related to executive control in adults with this disorder. Executive control functions that have been examined are for example, delay of reward aversion (Plichta et al., 2009), sustained and transient attentional control (Banich et al., 2009), cognitive interference (Bush et al., 1999), response inhibition and feedback processing (Dibbets, Evers, Hurks, Marchetta, \& Jolles, 2009), and working memory load (Hale, Bookheimer, McGough, Phillips, \& McCracken, 2007; Valera, Faraone, Biederman, Poldrack, \& Seidman, 2005). These studies reveal that, compared with normal controls, adults with ADHD display aberrant brain activity patterns in several brain areas during the performance of a cognitive task. The most common observations are activity changes in the dorsolateral prefrontal cortex (DLPFC), with both increased (Hale et al., 2007) and decreased (Banich et al., 2009; Bush et al., 1999) activity; decreased activity of medial cingulate 
areas (Banich et al., 2009; Bush et al., 1999); hyporesponsiveness in the ventral-striatal reward system, including the nucleus accumbens (Dibbets et al., 2009; Plichta et al., 2009); hyperactivity in dorsal parts of the striatum, including the caudate nucleus (Bush et al., 1999; Plichta et al., 2009) and putamen (Bush et al., 1999); and increased thalamic (Banich et al., 2009; Bush et al., 1999) and insular activity (Bush et al., 1999).

The present study was set up to further investigate brain activation in adults with ADHD during the performance of a task measuring another aspect of executive control, notably switching between response rules and tasks.

The task used for this study is based on a task-switching paradigm (Dibbets, Bakker, \& Jolles, 2006; Dibbets \& Jolles, 2006). This paradigm involves the induction of a response-conflict situation and is, therefore, appropriate for exploration of executive (dys)control. In this task, two relatively easy tasks are presented (Monsell, 1996; Rogers \& Monsell, 1995). In the "nonswitch" condition, the participant is repeatedly presented one of the two tasks (e.g., AAAA or BBBB). In the other condition, the "switch" condition, the participant switches from one task to the other (e.g., ABBABA). Performance is usually slower and less accurate in the switch than in the nonswitch condition. These so-called switch costs, expressed as the difference in performance between the switch and nonswitch conditions, are thought to reflect a stronger engagement of executive processes during the switch condition, such as the inhibition of the irrelevant task set and the accompanying response, switching to the relevant task set, and the maintenance and manipulation of two different mental task sets in working memory (Rogers \& Monsell, 1995). A deficit in executive control will, therefore, mostly be pronounced in the switch condition and not, or to a lesser extent, in the nonswitch condition. As a result, the switch costs will be enlarged in individuals with ADHD. This increase in switch costs is exactly what has been observed in children (Cepeda, Cepeda, \& Kramer, 2000) and adults with ADHD (White \& Shah, 2006).

Several functional MRI (fMRI) studies have examined task switching in normal adults (e.g., DiGirolamo et al., 2001; Dove, Pollmann, Schubert, Wiggins, \& von Cramon, 2000; Ruge et al., 2005; Rushworth, Hadland, Paus, \& Sipila, 2002). Additional activity during the switch condition was mainly observed in the dorsolateral and medial-frontal areas, the presupplementary motor area, cingulate areas, the caudate nucleus, and parietal areas. Except for the parietal areas, all these structures are involved in the frontostriatal circuitry, which is known to be affected in ADHD (Bradshaw, 2001). Indeed, an fMRI study on task switching in adolescents and children with ADHD revealed, among other changes in activation, underactivation of the PFC compared with healthy controls (Smith, Taylor, Brammer, Toone, \& Rubia, 2006). Separate group analyses of switch minus nonswitch trials indicated that healthy controls additionally recruited striatal areas, such as the caudate nucleus and putamen; no such additional activity in these areas was observed in the ADHD group. These results indicate that a task-switching paradigm can detect anomalies in the frontostriatal circuitry associated with ADHD. The main aim of the present study was to further investigate neural activity in adult ADHD using a task-switching paradigm. Based on previous research, it was hypothesized that-compared with normal controls-adults with ADHD should display a different neural activation pattern in the frontostriatal circuitry and parietal areas.
More specifically, it was expected that, compared with healthy controls, adults with ADHD should display aberrant activity in lateral and medial prefrontal areas, the caudate nucleus, putamen, and parietal cortex.

\section{Method and Materials}

This study was part of a larger project on ADHD and executive control in children (e.g., Hurks et al., 2004) and adults (e.g., Marchetta, Hurks, De Sonneville, Krabbendam, \& Jolles, 2008; Marchetta, Hurks, Krabbendam, \& Jolles, 2008). A part of our data concerning feedback- and inhibition-related brain activity in adult ADHD has been published elsewhere (Dibbets et al., 2009).

\section{Participants}

The study sample $(N=34)$ existed of two groups: 17 adults with ADHD and 17 education level- and age-matched normal controls. The ADHD group consisted of 16 persons with combined attention and hyperactivity problems (ADHD) and one adult with predominantly inattentive symptoms (attention deficit disorder [ADD]). All participants were male and right-handed. The reason for selecting only male participants was to create a more homogeneous sample as the menstrual cycle can influence both neuropsychological and neurophysiological parameters, including cortical activation patterns (e.g., Dietrich et al., 2001). The mean age of the ADHD group was 28.8 years $(S D=6.25$, range $=21.9-41.9)$, and 28.6 years $(S D=6.45$, range $=21.3-41.3)$ for the control group. The education level was $5.00(S D=1.62$, range $=2-7)$ for the ADHD group and $5.29(S D=1.40$, range $=3-8)$ for the control group, representing an average level of preuniversity education (De Bie, 1987).

Control participants were recruited via advertisements in local newspapers. Participants of the ADHD group were recruited by spreading information brochures after group interventions for adults with ADHD and by advertisements on Web sites of ADHD associations. Only participants in the group intervention that had no other Axis I or II diagnosis were approached for participation. Prior to the group intervention, diagnosis was set by an experienced ADHD team including a psychiatrist, a clinical psychologist, a neuropsychologist, and a registered psychiatric nurse. Briefly, the clinical assessment included a standard diagnostic protocol, including a clinical, semistructured interview with both the patient and a cross-informant (usually a parent or a spouse). At the very least, some elements of this interview were conducted by all disciplines separately. In these interviews, the following topics were collected: demographic, academic, and work history; developmental course; the Diagnostic and Statistical Manual of Mental Disorders (4th ed. [DSM-IV]) ADHD symptoms and criteria, as well as ADHD-related cognitive complaints, for example, executive dysfunctions; and the comorbid or co-occurring psychopathology. In addition, self-report rating scales, including a Dutch version of the Wender Utah Rating Scale (Ward, Wender, \& Reimherr, 1993) and a Dutch version of the ADHD Rating Scale based on the DSM-IV criteria (comparable to the one described in the Questionnaires and Neuropsychological Tests section), were completed. An extended neuropsychological examination (e.g., intelligence, attention, inhibitory control, and learning) and a review of school reports, if available, were also part of the assessment. Final 
diagnosis was based on clinical consensus in which all the data mentioned above were judged. This multidisciplinary procedure is in line with earlier published reports on classifying ADHD in adults (e.g., Barkley, 2005; Kooij et al., 2008). Subsequently, each ADHD participant received, next to the information package, a letter emphasizing that only "pure" ADHD participants were invited to respond. In addition, we asked each ADHD participant to provide a medical or diagnostic report of a (former) specialist or general practitioner. Unfortunately, only nine reports were received. However, this was not considered a problem as these reports served only as an additional control measure. Finally, all participants were asked via a short interview whether they had any other disorders in addition to the diagnosed ADHD. This whole procedure resulted in the following distribution of co-occurring characteristics, that is, no full DSM-IV classification: ADHD and depressive symptoms $(n=2)$, ADHD and obsessive-compulsive symptoms $(n=1)$, ADHD and substance abuse (cannabis, $n=1$ ), and ADHD and learning problems (dyslexia, $n=1$ ). Furthermore, one participant received epilepsy medication (Depakine) in addition to Ritalin to reduce ADHDrelated complaints, one received antihistamine, and one cholesterol medication. Fourteen ADHD participants used methylphenidatebased medication (Ritalin $n=11$; Concerta $n=3$ ). None of the control participants reported Axis I or II problems. One control participant reported the use of antiasthma medication (Seritide discus).

Exclusion criteria for all participants were presence of any current Axis I psychiatric diagnosis other than ADHD, IQ $<80$ (based on education level and Wechsler Adult Intelligence ScaleRevised [WAIS-R] Block Design; see below), neurological trauma or disorder, and contraindication for MRI. On suspicion of ADHD problems in the control group during testing, the Current Symptoms Scale and Childhood Symptoms Scale was administered to all participants (ADHD and controls) after completion of the experiment (see description in Neuropsychological Tests below). This checklist enabled verification of the presence of ADHD problems in the ADHD group and the absence of these problems in the control group. Inclusion criteria for the ADHD group were a minimum score of six symptoms on at least one of the current symptoms subscales and retrospective childhood subscales (Barkley \& Murphy, 1998). Inclusion criteria for the control group were a maximum of two symptoms on each of the current symptoms scales and a maximum of three symptoms on each of the retrospective childhood subscales (mean norm scores; Barkley \& Murphy, 1998).

The study was carried out in accordance with the Declaration of Helsinki and was started after approval of the local Medical Ethical Committee (Academic Hospital Maastricht, azM, the Netherlands, nr: 05.045.4). Before onset of the study, all participants provided written informed consent. Each participant was paid 50 Euros and received a compact disk with their anatomical brain scan.

\section{Questionnaires and Neuropsychological Tests}

The Current Symptoms Scale and Childhood Symptoms Scale (Barkley \& Murphy, 1998). The Current Symptoms Scale and Childhood Symptoms Scale is a short, self-report screening questionnaire to measure ADHD in adults. The questions are based on the ADHD symptom list of the DSM-IV (normative data are published in Barkley \& Murphy, 1998). The questionnaire contains a list concerning current symptoms of ADHD and a retrospective list concerning symptoms during childhood. For the present study, participants with ADHD were provided with two copies of the current symptoms list, one copy to fill in judging their behavior while using ADHD medication, one copy for judging their behavior during an off-medication period. All control participants received only one current symptoms list. In addition, all participants received one retrospective list containing items related to childhood behavior. Each list contains nine items measuring inattention and nine items measuring hyperactivity (six items) and impulsivity (three items) problems. Each item can be scored on a 4-point-scale ranging from 1 (never) to 4 (very often) A score is considered a symptom if an item is answered with often or very often, leading to a maximum of nine symptoms for inattention and nine symptoms for hyperactivity/impulsivity (Barkley \& Murphy, 1998).

The WAIS-R Block Design (Uterwijk, 2000). The Block Design subtest of the WAIS-R measures visuospatial abilities and is frequently used as an estimator of general intelligence (Kaufman \& Lichtenberger, 1999). Furthermore, if matched for level of education, no difference in performance on the WAIS-R Block Design between adults with ADHD and normal control is expected (Bridgett \& Walker, 2006; Seidman, Biederman, Weber, Hatch, \& Faraone, 1998). Therefore, in the present study, where groups were matched for level of education, WAIS-R Block Design was used to check for similar levels of general intelligence in each group, or in case a difference was observed between the groups, it functioned as a covariate in the data analyses.

\section{Functional MRI Task: The Switch Task (ST)}

The stimuli were presented on a screen and viewed via a mirror mounted on the head coil. The software used was programmed in E-prime (Psychology Software Tools, Version 1.1.4.4, http://www .pstnet.com/). The task used was the Switch Task (ST), which was developed at our department (for a detailed description, see Dibbets et al., 2006; Dibbets \& Jolles, 2006). This relatively easy task is based on a standard switch paradigm and can be used in studies with children and adults. The ST is presented as a simple computer game and consists of two similar, yet conflicting, tasks: the "day task" and the "night task" (see Figure 1).

During the day task, an orange house and a blue house with a white cat in between them were presented against a daytime sky. The left and right position of the houses varied across trials. One of the two houses could be selected by pressing the accompanying button (i.e., left or right). The role of the orange and blue house and the order of the day and night tasks were counterbalanced. For sake of brevity, only one version is described. During the day task, selecting the orange house (i.e., the correct response) was rewarded by replacing this house with a treasure chest. Selecting the blue house (i.e., the incorrect response) was punished by marking this house with a pink cross. The absence of a response was neither rewarded nor punished. During the night task, the houses and cat were presented against a nighttime sky and selection of the blue house was rewarded and selection of the orange house was punished.

The duration of each trial was 6,500 ms ( 2 TRs, repetition time between successive pulses applied to the same brain slice) and 


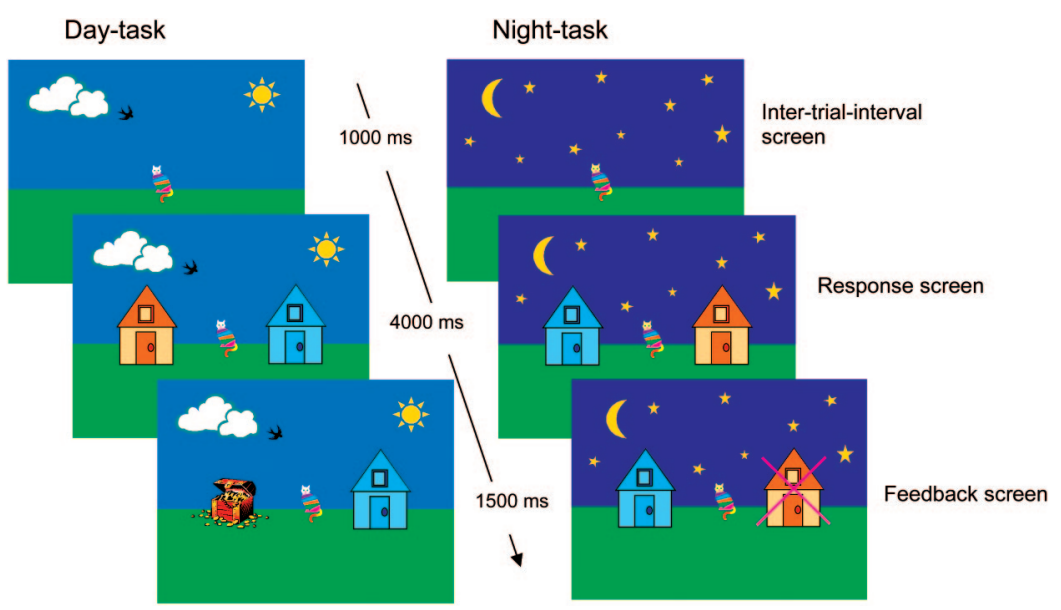

Figure 1. The Switch Task: On the left side is an example of a correct trial of the day task, on the right side an example of an incorrect trial of the night task. Note that the maximum response time is $4,000 \mathrm{~ms}$; if the participant responds within this time limit, the intertrial duration is proportionally enlarged to fill up to the total trial time to $6,500 \mathrm{~ms}$.

both response time (RT) and response accuracy were recorded. During the scan session, two experimental conditions were presented: the nonswitch condition and switch condition (block design). In the nonswitch condition, one task was repeatedly presented for eight trials (e.g., day-day-day or night-night-night). In the switch condition, eight trials of day and night were randomly mixed (e.g., day-night-night-day-night). Within each switch block, at least five switches between day and night took place ( $M=5.25$ switches per block). A signal screen before each block indicated whether only the day task, only the night task, or a mix of both tasks would be presented for the next eight trials. A total of eight 8 -trial blocks was presented with alternating nonswitch (total $=4$ blocks) and switch conditions (total $=4$ blocks). The onset of each block was synchronized with the scanner and the time between two blocks was at least $6 \mathrm{~s}$. During the scan session, the white cat on the screen was gradually filled with colors to give an indication of the remaining test time. The task started with a baseline condition (15 TRs) in which no response was required. The participants viewed a picture of a crown covered with gems placed in the center of a green screen. During this baseline, some of the gems occasionally sparkled (on average, seven sparkles) to preserve attention to the picture. The participant was instructed to passively watch the scene. The task lasted for $10 \mathrm{~min}$. The ST was practiced in a simulation scanner about 2 weeks prior to the actual scan session. This practice version was identical to the scan version with the exception that no baseline was presented.

\section{MRI Scanning}

The participants were scanned using a $1.5 \mathrm{~T}$ MRI whole-body scanner (Philips Gyroscan ACS-NT, Eindhoven, the Netherlands) with a synergy head coil. Head fixation was accomplished by using foam padding. Each scan session started with a sagittal T1weighted anatomical image ( 150 slices, imaging matrix $=256 \times$ 256, slice thickness $1 \mathrm{~mm}$, no gap) directly followed by the ST. Functional images were based on a $\mathrm{T}^{*}$ weighted gradient echo sequence with the following parameters: flip angle $=90^{\circ}, \mathrm{TE}=48$ $\mathrm{ms}, \mathrm{TR}=3,250 \mathrm{~ms}$, field of view $=224 \times 224$, imaging matrix $=$ $128 \times 128$, slice thickness $=3 \mathrm{~mm}$, slice gap $=0 \mathrm{~mm}$, 32 slices. Scanning orientation was axial and slice order was interleaved. A total of 185 volumes was collected.

\section{Procedure}

The experiment was conducted in two 2-hr sessions, about 2 weeks apart. In Session 1, the ST was practiced in a simulation scanner and the Block Design subtest of the WAIS-R was administered. Participants with ADHD were requested to refrain from any ADHD medication at least $24 \mathrm{hr}$ prior to the second session, during which anatomical and functional scans were made. After completion of the entire experiment, all participants were asked to complete the Current Symptoms Scale and Childhood Symptoms Scale.

\section{Behavioral Data Analysis}

The WAIS-R Block Design data were transformed to standard $T$ scores (standardized mean $=50, S D=10$ ). Dependent measures of the ST were the total number of errors per condition, including omissions, and the mean RT of correct responses in each condition (nonswitch and switch). Switch costs were calculated by subtracting the mean RT in the nonswitch condition from the mean RT in the switch condition (RT costs), and error costs were calculated by subtracting the total number of errors in the nonswitch condition from the total number of errors in the switch condition.

The data of the WAIS-R Block Design, the symptom checklists, and ST were analyzed for group differences using parametric tests (analysis of variance [ANOVA] and repeated measures general linear model [GLM]). In each analysis, group (ADHD vs. control) functioned as a between-subjects factor. In the repeated measures GLM, condition (switch vs. nonswitch) served as a within-subject factor. Partial eta squared $\left(\eta_{\mathrm{p}}^{2}\right)$ was used as a measure for effect size. Bonferroni tests were used to adjust the significance level when multiple comparisons were made. The rejection criterion was set at $p<.05$. 


\section{Image Analysis}

The fMRI data were statistically analyzed using Brainvoyager QX Version 1.10.4.1250 software (Brain Innovation, Maastricht, the Netherlands). Preprocessing procedures consisted of 3D motion correction, slice time correction, spatial Gaussian smoothing (FWHM $8 \mathrm{~mm}$ ), and temporal filtering (highpass filter: 3 cycles/ block and linear trend removal). For each participant, functional and anatomical images were spatially coregistered and transformed to standard Talairach space (Talairach \& Tournoux, 1988). After individual GLM analyses, we ran a random effect analysis (separate subject predictors, $z$ transformation) to assess task-related activity and to detect differences in brain activity between the ADHD and control groups. In this model, two predictors were incorporated, the switch and nonswitch conditions. These predictors were obtained using a model of the hemodynamic response locked to the onset of each block. For each participant, a general response level was estimated and activation on the predictors was expressed relative to this baseline value. Subsequently, a random effects analysis of covariance (ANCOVA) was run using the random effect multisubject GLM as input. In this analysis, the nonswitch and switch condition served as within-subjects factor and group (ADHD vs. control) functioned as a between-subjects factor. Finally, overlay random effects ANCOVAs were used to map the several contrasts (see below). Cluster-level thresholding (1,000 iterations) was applied as a correction method for multiple comparisons and to reduce the likelihood of Type I errors to less than .05 (Forman et al., 1995; Goebel, Esposito, \& Formisano, 2006). Effect sizes were calculated using $\eta_{\mathrm{p}}^{2}$. All analyses were whole-brain analyses.
Brain activity related to task switching was assessed by comparing the switch blocks with the nonswitch blocks. This taskrelated contrast was calculated for all data (two groups together). Next, differences in switch-related activity (switch-nonswitch) between groups were assessed. Anatomical labeling of the clusters was carried out using the Talairach and Tournoux atlas (1988).

\section{Results}

\section{Demographic and Neuropsychological Data}

Five participants were excluded. The participant with predominantly attention problems displayed too few symptoms of $\mathrm{AD}(\mathrm{H}) \mathrm{D}$ on the current and childhood subscales of the Current Symptoms Scale and Childhood Symptoms Scale (maximum of three symptoms per scale). Three participants of the control group displayed too many ADHD symptoms (five or more symptoms on the current or childhood subscale). Finally, one ADHD participant was excluded because of very poor task performance, indicating either a lack of motivation or poor task comprehension, which could also have effects on the brain activity observed. The average RT of this participant $(1,804 \mathrm{~ms})$ on the ST deviated more than 5 standard deviations from the remainder of included ADHD participants $(M=826 \mathrm{~ms}, S D=181)$, the total number of errors (only one error) deviated less than 1 standard deviation from the group $(M=3.07, S D=2.25)$. Both of the two excluded $\mathrm{AD}(\mathrm{H}) \mathrm{D}$ participants used Ritalin and both reported only ADHD-related symptoms. Table 1 summarizes the demographic and neuropsychological data of the remaining participants (14 controls; 15 ADHD). The two groups did not significantly differ with regard to age, education level, and

Table 1

Demographic and Behavioral Data for the ADHD and Control Groups

\begin{tabular}{lcr}
\hline \multicolumn{1}{c}{ Variable } & ADHD $(n=15)$ & Control $(n=14)$ \\
\hline Mean $(S D)$ age (years) & $28.9(6.5)$ & $28.8(6.2)$ \\
Mean $(S D)$ education level & $5.6(1.3)$ & $4.7(2.8)$ \\
Mean $(S D)$ Block Design $T$ score & $65.3(7.3)$ & $66.4(8.3)$ \\
Medication, $n$ & & 0 \\
Ritalin/Concerta & $9 / 3$ & 0 \\
Cannabis & 1 & \\
Other & & $0.36^{*}(1.34)$ \\
Mean $(S D)$ current symptoms & $6.33^{*}(2.64)$ & $1.07^{*}(2.30)$ \\
No medication inattention & $6.27^{*}(2.09)$ & \\
No medication hyperactivity/impulsivity & $1.27(1.39)$ & \\
Medication inattention & $1.73(1.98)$ & $0.70^{*}(1.06)$ \\
Medication hyperactivity/impulsivity & $6.20^{*}(3.21)$ & $0.59^{*}(1.76)$ \\
Mean $(S D)$ childhood symptoms & $6.27^{*}(2.09)$ & $848.3(242.0)$ \\
Inattention & & $691.2(199.0)$ \\
Hyperactivity/impulsivity & $889.6(177.9)$ & $769.6(219.1)$ \\
Mean $(S D)$ ST RTs & $764.5(193.1)$ & $157.2(71.4)$ \\
Switch & $826.0(181.3)$ & $0.71(0.91)$ \\
Nonswitch & $125.1(81.0)$ & $0.50(0.94)$ \\
Total RT & $1.93(2.02)$ & $1.21^{*}(1.05)$ \\
RT cost & $1.13(1.36)$ & \\
Mean $(S D)$ ST errors (total per condition) & $3.07^{*}(2.25)$ & \\
Switch & & \\
Nonswitch & &
\end{tabular}

Note. $\quad \mathrm{ADHD}=$ attention-deficit/hyperactivity disorder; $\mathrm{ST}=$ Switch Task; $\mathrm{RT}=$ response time; Current symptoms $=$ Current Symptoms Scale; childhood symptoms $=$ Childhood Symptoms Scale.

* Significant difference between the ADHD and control group, $p<.05$. 
WAIS-R Block Design score, $F_{\mathrm{S}}(1,28)<1.54$. As expected, the ADHD group displayed more inattentive and hyperactivity impulsivity symptoms on the Current Symptoms Scale and Childhood Symptoms Scale, $F_{\mathrm{s}}(1,28)>40.63, p \mathrm{~s}<.001, \eta_{\mathrm{p}}^{2}>.58$. ADHD participants scored themselves as less inattentive and hyperactive during an on-medication period, $F \mathrm{~s}(1,14)>38.25, p \mathrm{~s}<.001, \eta_{\mathrm{p}}^{2}>.73$, compared with an off-medication period.

\section{The Switch Task (ST)}

Table 1 summarizes the mean RTs and errors for each group on the ST. As expected, the analysis of the RTs revealed that participants responded faster in the nonswitch than in the switch condition, $F(1$, $27)=98.46, p<.001, \eta_{\mathrm{p}}^{2}=.78$. No group effect or Group $\times$ Condition interaction was observed, $F \mathrm{~s}(1,27)<1.27, p \mathrm{~s}>.27$. A separate analysis of the RT costs revealed no difference in switch costs between the two groups, $F(1,28)=1.27, p=.27$, indicating no specific executive control deficit in the ADHD group.

The analysis of the total number of errors in each condition revealed that the ADHD group made, overall, significantly more errors (range $=0-7$ ) than did the control group (range $=0-3$ ), $F(1,27)=7.87, p<.01, \eta_{\mathrm{p}}^{2}>.23$. No main effect of condition or Group $\times$ Condition interaction was observed, $F \mathrm{~s}(1,27)<1.28$, $p$ s $>.21$. Because of the low error rates, no error costs were calculated. These results indicate that the increase of errors in the ADHD group was not specific for the switch condition. A closer look at the type of errors made revealed that in both groups more than $80 \%$ of the errors were caused by selecting the incorrect house and less than $20 \%$ through response omission. This distribution was similar in both groups, $F_{\mathrm{S}}<1$.

\section{Neuroimaging}

For all participants, the amount of movement was within acceptable ranges ( < voxel size). Analyses of the six parameters generated during motion correction revealed no significant group differences in absolute mean translation movement (ADHD, $0.16 \pm 0.26 \mathrm{~mm}$; control, $0.19 \pm 0.20 \mathrm{~mm}$ ) and the absolute mean rotation movement (ADHD, $0.18 \pm 0.21$ degrees; control, $0.20 \pm 0.27$ degrees), $F_{\mathrm{s}}<1$.

\section{Task-Related Activity: Switch Versus Nonswitch}

The comparison of the switch condition versus the nonswitch condition represents the neural correlates of additional cognitive processes related to task switching. For results, see Table 2. Three large task-related activation clusters were observed in the right superior frontal gyrus (BA 6), the left superior parietal lobule (BA 7 ), and the left orbitofrontal cortex (BA 47).

\section{Group Differences in Task Switching}

Table 3 and Figure 2 display the interaction between group and condition. This interaction reflects group differences in additional brain activation associated with task switching (switch vs. nonswitch). The ADHD group revealed more activation than did the control group in the right middle temporal gyrus (BA 19), the right dorsal anterior cingulate cortex (BA 32), the right precuneus (BA 31 ), the right lingual gyrus (BA 17), the left precentral gyrus (BA 6, supplementary motor area), and the left insula (BA 13). The control group displayed more activation in the right putamen, the right dorsal posterior cingulate cortex (BA 31), the left medial frontal cortex (BA 6), the right thalamus, the left orbitofrontal cortex (BA 47) extending to the claustrum, and the postcentral gyrus (BA 2).

\section{Discussion}

The present fMRI study evaluated differences in brain activity between normal adults and adults with ADHD during the performance of a task-switching paradigm, the ST. In this task, participants had to switch between two similar yet conflicting tasks (switch condition) or perform only one of these two tasks (nonswitch condition). The behavioral data of the ST are in line with other task-switching studies (Allport, Styles, \& Hsieh, 1994; Dibbets \& Jolles, 2006). That is, both groups responded slower in the switch than in the nonswitch condition, reflecting a stronger engagement of executive control processes during the switch condition. However, contrary to previous studies, no specific executive control deficits were observed in the ADHD group (e.g., White \& Shah, 2006). The switch costs, defined as a difference in RT or error performance between the switch and nonswitch conditions, did not differ between the control and ADHD groups. The only group difference was a higher overall error rate for the ADHD group ( $M=3.1$ errors) compared with the control group $(M=1.2$ errors). Although the absence of a difference in switch costs between the two groups was somewhat unexpected, this lack of an executive deficit has been observed more often in adolescents (Smith et al., 2006) and adults with ADHD (for reviews, see Boonstra, Oosterlaan, Sergeant, \& Buitelaar, 2005; Woods, Lovejoy, \& Ball, 2002). Altogether, the behavioral data of the ST do not provide evidence for a specific executive control deficit in adults with ADHD, but suggest a more general information-processing deficit such as attention or inhibition problems.

Task-related brain activation (switch vs. nonswitch condition) was observed in large clusters in the right superior frontal gyrus, the left superior parietal lobule, and the inferior frontal (ventrolateral PFC) gyrus extending to the claustrum. These results concord

Table 2

Brain Regions Showing Greater Activation During the Switch Condition Compared With the Nonswitch Condition (Whole-Brain Analyses)

\begin{tabular}{lcccclr}
\hline \multicolumn{1}{c}{ TAL } & Cluster size & $T$ & $p$ & $\eta_{\mathrm{p}}^{2}$ & \multicolumn{1}{c}{ Brain region } & BA \\
\hline$[13,15,65]$ & 2,619 & 3.69 & .0005 & .29 & Superior frontal gyrus & 6 \\
{$[-22,-57,32]$} & 1,350 & 3.74 & .0004 & .29 & Superior parietal lobule & 7 \\
{$[-26,25,0]$} & 1,512 & 3.73 & .0005 & .27 & Inferior frontal gyrus/claustrum & 47 \\
\hline
\end{tabular}

Note. Switch-nonswitch: attention-deficit/hyperactivity disorder (ADHD) and controls $(n=29)$. The cluster size is expressed in anatomical voxels $(1 \times 1 \times 1 \mathrm{~mm})$. TAL $=$ Talairach coordinates $(\mathrm{x}, \mathrm{y}, \mathrm{z})$; $\mathrm{BA}=$ Brodmann Areas. 
Table 3

Differences in Brain Activation During the Switch Task Between the ADHD and the Control Groups (Whole-Brain Analyses)

\begin{tabular}{|c|c|c|c|c|c|c|}
\hline TAL & Cluster size & $T$ & $p$ & $\eta_{p}^{2}$ & Brain region & BA \\
\hline \multicolumn{7}{|l|}{ ADHD $>$ controls } \\
\hline$[38,-57,18]$ & 1,323 & 3.14 & .003 & .25 & Middle temporal gyrus & 19 \\
\hline$[22,31,24]$ & 1,620 & 3.40 & .001 & .30 & Anterior cingulate gyrus & 32 \\
\hline$[14,-54,30]$ & 1,566 & 3.83 & .0003 & .21 & Precuneus & 31 \\
\hline$[19,-82,0]$ & 1,323 & 3.58 & .0007 & .28 & Lingual gyrus & 17 \\
\hline$[-35,-12,33]$ & 4,347 & 4.21 & .00009 & .31 & Precentral gyrus & 6 \\
\hline$[-29,-39,21]$ & 2,430 & 4.53 & .00003 & .39 & Insula & 13 \\
\hline \multicolumn{7}{|l|}{ Controls $>$ ADHD } \\
\hline$[23,6,2]$ & 10,260 & 4.02 & .0002 & .46 & Putamen & \\
\hline$[20,-30,44]$ & 1,809 & 3.80 & .0004 & .34 & Cingulate gyrus & 31 \\
\hline$[-10,-3,56]$ & 13,743 & 4.27 & .00008 & .55 & Medial frontal gyrus & 6 \\
\hline$[3,-12,11]$ & 2,673 & 3.66 & .0006 & .42 & Thalamus & \\
\hline$[-28,11,-4]$ & 1,998 & 3.39 & .001 & .27 & Inferior frontal gyrus/claustrum & 47 \\
\hline$[-35,-30,33]$ & 1,539 & 3.64 & .0006 & .27 & Postcentral gyrus & 2 \\
\hline
\end{tabular}

Note. $\mathrm{ADHD}=$ attention-deficit/hyperactivity disorder. The cluster size is expressed in anatomical voxels $(1 \times 1 \times 1 \mathrm{~mm})$. TAL $=$ Talairach coordinates $(\mathrm{x}, \mathrm{y}, \mathrm{z}) ; \mathrm{BA}=$ Brodmann Areas.

with results of other imaging studies examining task switching (Braver, Reynolds, \& Donaldson, 2003; Crone, Wendelken, Donohue, \& Bunge, 2006; DiGirolamo et al., 2001).

The most important comparison of the present study was that of the task-related activation differences, that is, the switch-nonswitch activation, between the ADHD and healthy controls. This contrast revealed that adults with ADHD more strongly engaged the right middle temporal gyrus, dorsal anterior cingulate cortex (dACC), precuneus, lingual gyrus, and the left precentral gyrus (supplementary motor area) and insula during task switching. Remarkably, the controls also engaged these regions, but during the nonswitch rather than the switch condition, $F \mathrm{~s}>6.71, p \mathrm{~s}<$ $.05, \eta_{\mathrm{p}}^{2}>.31$. Controls more strongly engaged the right putamen, dorsal posterior cingulate cortex, thalamus, and the left medial frontal gyrus, orbitofrontal cortex (ventrolateral PFC), and postcentral gyrus. Likewise, these areas were also engaged in the ADHD group, but rather during the nonswitch than switch condition, $F \mathrm{~s}>7.46, p \mathrm{~s}<.05, \eta_{\mathrm{p}}^{2}>.34$, but, inferior frontal gyrus, $F(1$, $14)=4.32, p=.057$. An ad hoc analysis of the $\beta$ values of each cluster with the switch condition of one group and the nonswitch condition of the other group as between-subjects factors revealed a similar pattern. Only one cluster revealed a group difference, that is, the activity in the medial frontal gyrus was higher in the nonswitch condition of the ADHD compared with the switch condition of the control group, $t=3.31, p<.005$. This might indicate that similar brain areas are involved during the switch task, but that the conditions that evoke the recruitment of these areas differ between the control and ADHD groups.

The results confirm our hypothesis that adults with ADHD should display different frontostriatal and parietal activation than healthy controls during the performance of an executive control task. Furthermore, the data concord with other adult ADHD studies in that the ADHD group showed a relative decrease in activation in the thalamus (Banich et al., 2009), posterior cingulate gyrus (Hale et al., 2007), and inferior frontal gyrus (Banich et al., 2009; Hale et al., 2007). A relative increase was observed in the precentral gyrus (Sunshine et al., 1997), temporal areas (Banich et al., 2009; Hale et al., 2007), and the insula (Banich et al., 2009; Bush et al., 1999). Compared with our go/no-go task, in which almost the same research sample was used, only one corresponding region was observed. During positive feedback, the ADHD group displayed less activation in the left inferior frontal cortex (orbitofrontal part) compared with the healthy controls. No other similarities were detected.

A more important comparison is that with the neuroimaging study of Smith and colleagues (2006). In that study, adolescents with ADHD and healthy controls performed a switch task. Although their group results deviate from the present data, the separate group analyses of Smith et al. do show similarities. That is, compared with the healthy controls, the ADHD group additionally recruited the dACC during task switching but failed to activate the putamen.

The most remarkable result of the present study is the increase rather than decrease in activation of the dACC in the ADHD group. Even though the study of Smith et al. (2006) also observed this increase, most functional neuroimaging studies report a hypofunctioning of the dACC in ADHD (for reviews, see Bush et al., 2005; Schneider, Retz, Coogan, Thome, \& Rosler, 2006). Neural activity of the dACC is associated with error responses and negative feedback (Holroyd et al., 2004). Although no specific executive control deficit was observed in the ADHD group, separate ANOVAs indicate that the ADHD group made significantly more errors during the switch condition, $F(1,28)=4.29, p<.05$, but not during the nonswitch condition $(p=.16)$, than did the control group. It is, therefore, possible that the observed increase in the dACC in the ADHD group is caused by this difference in errors and the accompanying negative feedback. Although this might seem a sound explanation, one has to bear in mind that the number of errors and negative feedback was small (ADHD $M=3.07$; controls $M=1.21$ ). In addition, a repeated measures GLM analysis with the extracted $\beta$ values ( $z$ transformation, baseline corrected, switch and nonswitch condition) from the ACC activity revealed that incorporating the total number of errors as a covariate did not abolish the observed Group $\times$ Condition interaction, $F(1$, 27) $=12.98, p<.005$.

Next to error and feedback processing, dACC activation is also strongly associated with the detection of conflicting information (for an overview, see Carter \& van Veen, 2007). It is suggested 

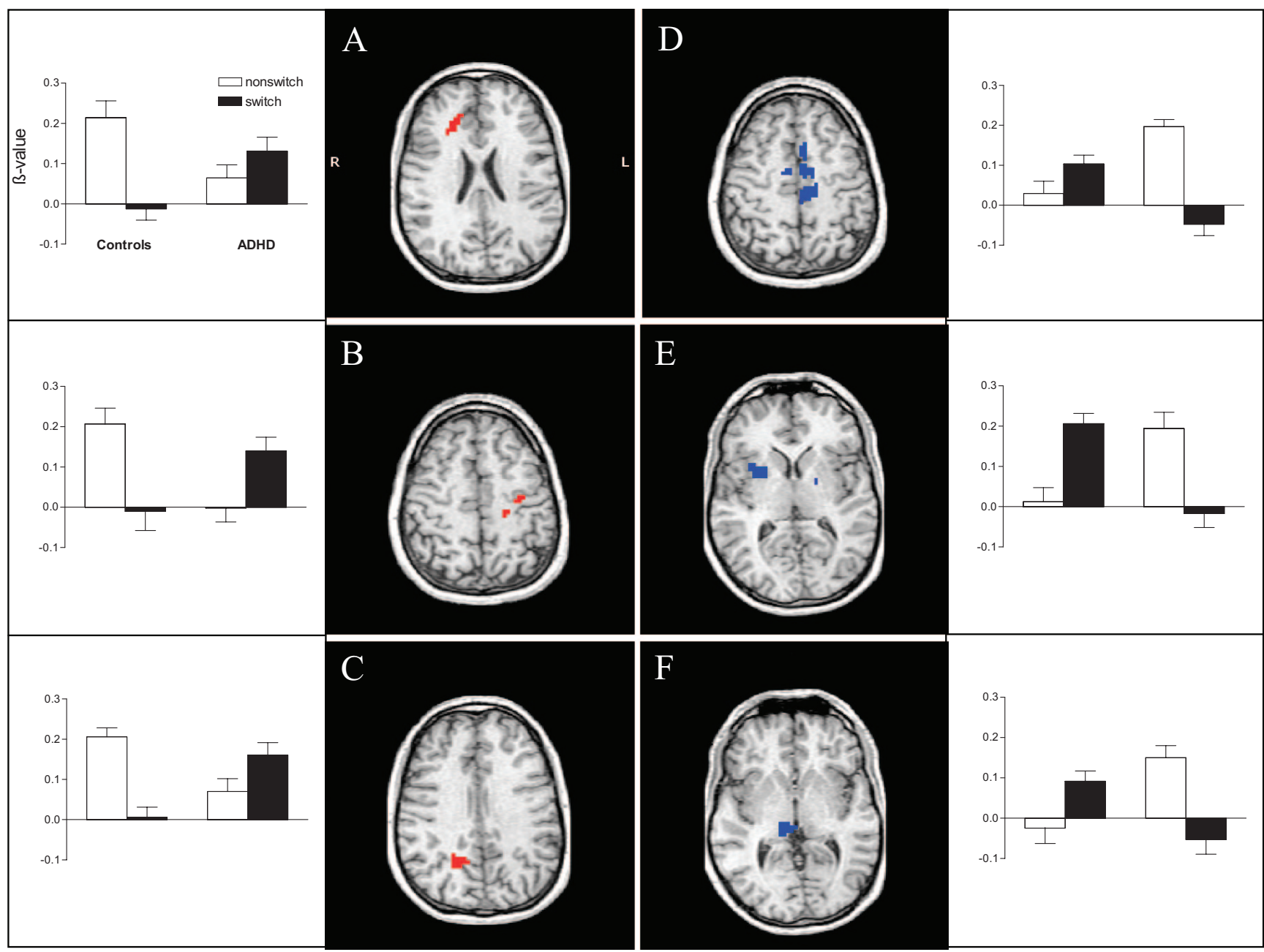

Figure 2. Differences in task-related activation (switch-nonswitch) between the attention-deficit/hyperactivity disorder (ADHD) and control groups (whole-brain analysis) and accompanying $\beta$ values. Red indicates more activation in the ADHD group, blue indicates more activation in the control group. $\mathrm{A}=$ anterior cingulate cortex; $\mathrm{B}=$ precentral gyrus; $\mathrm{C}=$ insula; $\mathrm{D}=$ medial frontal gyrus; $\mathrm{E}=$ putamen; and $\mathrm{F}=$ thalamus.

that following the detection of a conflict, the DLPFC is engaged in order to reduce this conflict. Task switching is known to induce response competition and, therefore, can result in the engagement of the dACC. As adults with ADHD experience more inhibition problems (Epstein et al., 2001; Murphy, 2002b; Ossmann \& Mulligan, 2003), one can argue that they more strongly engaged the dACC to reduce this conflict in order to perform at the same level as the control group. Unfortunately, no subsequent increase in the DLPFC in the ADHD group was observed to support this notion.

An alternative explanation is that the dACC was more strongly engaged to maintain the focus of attention. The study of Weissman, Gopalakrishnan, Hazlett, and Woldorff (2005) indicated a role for dACC in healthy participants in focusing attention on relevant stimuli, especially when distracting events are present. In the case of our study, one can argue that the ADHD group more strongly engaged the dACC to boost attention during the distracting switch condition in order to obtain a normal level of task performance. This attention-related explanation is in line with the changing nature of ADHD symptoms across time. As children with ADHD mature, hyperactivity/impulsivity symptoms decline, but inattentive symptoms remit in fewer cases (Biederman et al., 2000).

In line with the previous attentional explanation, more activity deviations were observed in attention-related brain structures. Attention can be subdivided in three relatively independent aspects, that is, alerting, orienting, and resolving conflict among responses (executive attention), each linked to separable brain areas (Posner \& Petersen, 1990). Structures that are associated with the alerting network are the right frontal lobe, right parietal lobe, thalamic areas, and locus coeruleus; the orienting network is associated with the parietal lobe and the fusiform gyrus; the executive attention network seems to include midline frontal areas including the ACC, supplementary motor area, and portions of the basal ganglia (Berger \& Posner, 2000; Fan, McCandliss, Fossella, Flombaum, \& Posner, 2005). Although the task used for the present study was not designed to measure separate attention aspects, we observed 
relatively increased activity in the ACC and supplementary motor area, and decreased activation in the putamen, inferior frontal gyrus, and medial frontal gyrus in the ADHD group. These structures are related to the executive attention network. In addition, we observed decreased activity in the thalamus, a structure that is involved in activation of the alerting network (e.g., Fan et al., 2005; for an overview, see Raz, 2004).

A final network that can be linked to ADHD symptoms is the default attention network proposed by Raichle and colleagues (2001). This network comprises a set of brain regions located at the midline areas of the brain (e.g., posterior cingulate gyrus, precuneus, medial PFC, and ACC; see also Fassbender et al., 2009) and is thought to suppress brain activity to allow goal-directed behavior. In accordance with this default network explanation, Fassbender and colleagues (2009) observed that increased distractibility in children with ADHD coincided with the inability to sufficiently suppress activity in the medial PFC, which is part of the default-mode attention network. In the present research, the amount of inattention (based on the Current Symptoms Scale) significantly correlated with an increase in activity during the complex switch condition (extracted $z$-transformed and normalized $\beta$ values) in the ACC, $\rho=0.543$, $p<.01$. That is, more attention problems coincided with more activity, which might indicate less suppression. This speculation is in line with the notion that default-mode network areas might be insufficiently suppressed in ADHD. However, contrary to the findings of Fassbender et al., medial frontal activity during the switch condition significantly correlated with fewer attention problems, $\rho=-0.423, p<.05$. No other significant correlations between attention problems and posterior cingulate and precuneus activity were observed, $p \mathrm{~s}>.10$. A possible explanation for this discrepancy is that, depending on the task, different suppression patterns are observed. In addition, it is thinkable that lack of suppression in the ACC evokes more suppression in other areas of the default-mode network, such as the medial PFC, in order to successfully accomplish the task.

Summarizing the results, it seems that the ADHD group showed a hypoactivation of the alerting system and more strongly engaged parts of the executive attention system. In addition, hypo- and hyperactivation in the default-mode attention network, linked to executive control, were observed. These results are in line with the notion that ADHD is characterized by deviations in the alerting, executive attention (Berger \& Posner, 2000), and default-mode networks (Fassbender et al., 2009). The increase in executive areas is probably to compensate for lapses of attention and to perform the task at the same level as normal adults.

Although the results are promising, the current study does have a number of limitations. First, the control participants were not screened as thoroughly as the ADHD participants. This might have resulted in a deviating control sample. Although we tried to correct this by excluding all participants with a relatively high inattention or hyperactivity/impulsivity score, this does not guarantee that the included participants did not have other (neuro)psychological problems. Therefore, in the future, we would strongly recommend using a standard neuropsychological assessment for all participants. Second, the baseline condition of the ST was not a traditional resting state, but involved watching a fluctuating visual presentation. This condition might have tapped cognitive processes, such as sustained attention, that are known to be disturbed in adults with ADHD (e.g., Marchetta, Hurks, De Sonneville, et al., 2008). The subtraction of this nonneutral baseline condition might have obscured possible group differences regarding these cognitive processes. Therefore, in a future experiment, a less cognitive demanding resting state should be incorporated. A third topic that needs to be mentioned is that a block rather than an event-related design was used. An advantage of an event-related design is that it can disentangle actual task-switching effects from working memory load effects. This can be accomplished by comparing the switch trials and nonswitch trials within a switch block (e.g., Kray \& Lindenberger, 2000). In the present study, this resulted in too few nonswitch events in the switch blocks for data analyses (seven nonswitch trials). The reason that we did not use an event-related design is that we plan to offer the current task to children and adolescents with ADHD in the near future. This will enable us to track developmental changes in brain activation patterns associated with task switching in ADHD. A pilot study in normal control children indicated that presenting the ST in an event-related fashion resulted in many errors, with some children not mastering the task at all.

In conclusion, the data from the present study add to the view that ADHD is associated with altered brain activation patterns in the frontostriatal circuitry during the performance of an executive control task. The expected deficit in executive control was not behaviorally expressed in enlarged switch costs, but visible as hypo- and hyperactivity of several brain regions. This discrepancy between behavioral and fMRI findings stresses the importance of the use of neuroimaging techniques in cognitive research. Not only do these techniques provide additional, otherwise unnoticed, information, they also create (future) clinical application possibilities, such as treatment evaluations.

\section{References}

Allport, D. A., Styles, E. A., \& Hsieh, S. (1994). Shifting intentional set: Exploring the dynamic control of tasks. In C. Umilta \& M. Moscovitch (Eds.), Attention and performance 15: Conscious and nonconscious information processing. Attention and performance series (pp. 421452). Cambridge, MA: MIT Press.

American Psychiatric Association. (1994). Diagnostic and statistical manual of mental disorders (4th ed.). Washington DC: Author.

Banich, M. T., Burgess, G. C., Depue, B. E., Ruzic, L., Bidwell, L. C., Hitt-Laustsen, S., . . W Willcutt, E. G. (2009). The neural basis of sustained and transient attentional control in young adults with ADHD. Neuropsychologia, 14, 3095-3104.

Barkley, R. A. (1996). Attention deficit-hyperactivity disorder. In E. J. Mash \& R. A. Barkley (Eds.), Child psychopathology (pp. 63-112). New York: Guilford Press.

Barkley, R. A. (2005). Attention-deficit hyperactivity disorder: A handbook for diagnosis and treatment (3rd ed.). New York: Guilford Press.

Barkley, R. A., \& Murphy, K. R. (1998). Attention-deficit hyperactivity disorder: A clinical workbook (2nd ed.). New York: Guilford Press.

Berger, A., \& Posner, M. I. (2000). Pathologies of brain attentional networks. Neuroscience \& Biobehavioral Reviews, 24, 3-5.

Biederman, J., Mick, E., \& Faraone, S. V. (2000). Age-dependent decline of symptoms of attention deficit hyperactivity disorder: Impact of remission definition and symptom type. The American Journal of Psychiatry, 157, 816-818.

Boonstra, A. M., Oosterlaan, J., Sergeant, J. A., \& Buitelaar, J. K. (2005). Executive functioning in adult ADHD: A meta-analytic review. Psychological Medicine, 35, 1097-1108. 
Bradshaw, J. L. (2001). Developmental disorders of the frontostriatal system: Neuropsychological, neuropsychiatric and evolutionary perspectives. Hove, England: Psychology Press.

Braver, T. S., Reynolds, J. R., \& Donaldson, D. I. (2003). Neural mechanisms of transient and sustained cognitive control during task switching. Neuron, 39, 713-726.

Bridgett, D. J., \& Walker, M. E. (2006). Intellectual functioning in adults with ADHD: A meta-analytic examination of full-scale IQ differences between adults with and without ADHD. Psychological Assessment, 18, $1-14$.

Bush, G., Frazier, J. A., Rauch, S. L., Seidman, L. J., Whalen, P. J., Jenike, M. A., .. Biederman, J. (1999). Anterior cingulate cortex dysfunction in attention-deficit/hyperactivity disorder revealed by fMRI and the Counting Stroop. Biological Psychiatry, 45, 1542-1552.

Bush, G., Valera, E. M., \& Seidman, L. J. (2005). Functional neuroimaging of attention-deficit/hyperactivity disorder: A review and suggested future directions. Biological Psychiatry, 57, 1273-1284.

Carter, C. S., \& van Veen, V. (2007). Anterior cingulate cortex and conflict detection: An update of theory and data. Cognitive, Affective, \& Behavioral Neuroscience, 7, 367-379.

Cepeda, N. J., Cepeda, M. L., \& Kramer, A. F. (2000). Task switching and attention deficit hyperactivity disorder. Journal of Abnormal Child Psychology, 28, 213-226.

Crone, E. A., Wendelken, C., Donohue, S. E., \& Bunge, S. A. (2006). Neural evidence for dissociable components of task-switching. Cerebral Cortex, 16, 475-486.

De Bie, S. E. (1987). Standaardvragen 1987: Voorstellen voor uniformering van vraagstellingen naar achtergrondkenmerken en interviews [Standard questions 1987: Proposal for uniformization of questions regarding background variables and interviews] (2nd ed.). Leiden, the Netherlands: Leiden University Press.

Dibbets, P., Bakker, K., \& Jolles, J. (2006). Functional MRI of task switching in children with specific language impairment (SLI). Neurocase, 12, 71-79.

Dibbets, P., Evers, L., Hurks, P., Marchetta, N., \& Jolles, J. (2009). Differences in feedback- and inhibition-related neural activity in adult ADHD. Brain and Cognition, 70, 73-83.

Dibbets, P., \& Jolles, J. (2006). The Switch Task for Children: Measuring mental flexibility in young children. Cognitive Development, 21, 60-71.

Dietrich, T., Krings, T., Neulen, J., Willmes, K., Erberich, S., Thron, A., \& Sturm, W. (2001). Effects of blood estrogen level on cortical activation patterns during cognitive activation as measured by functional MRI. NeuroImage, 13, 425-432.

DiGirolamo, G. J., Kramer, A. F., Barad, V., Cepeda, N. J., Weissman, D. H., Milham, M. P., . . . McAuley, E. (2001). General and task-specific frontal lobe recruitment in older adults during executive processes: A fMRI investigation of task-switching. NeuroReport, 12, 2065-2071.

Dove, A., Pollmann, S., Schubert, T., Wiggins, C. J., \& von Cramon, D. Y. (2000). Prefrontal cortex activation in task switching: An event-related fMRI study. Cognitive Brain Research, 9, 103-109.

Durston, S. (2003). A review of the biological bases of ADHD: What have we learned from imaging studies? Mental Retardation and Developmental Disabilities Research Reviews, 9, 184-195.

Epstein, J. N., Johnson, D. E., Varia, I. M., \& Conners, C. K. (2001). Neuropsychological assessment of response inhibition in adults with ADHD. Journal of Clinical and Experimental Neuropsychology, 23, $362-371$.

Fan, J., McCandliss, B. D., Fossella, J., Flombaum, J. I., \& Posner, M. I. (2005). The activation of attentional networks. Neurolmage, 26, 471479 .

Faraone, S. V., Biederman, J., Spencer, T., Wilens, T., Seidman, L. J., Mick, E., \& Doyle, A. E. (2000). Attention-deficit/hyperactivity disorder in adults: An overview. Biological Psychiatry, 48, 9-20.
Fassbender, C., Zhang, H., Buzy, W. M., Cortes, C. R., Mizuiri, D. Beckett, L., \& Schweitzer, J. B. (2009). A lack of default network suppression is linked to increased distractibility in ADHD. Brain Research, 1273, 114-128.

Forman, S. D., Cohen, J. D., Fitzgerald, M., Eddy, W. F., Mintun, M. A., \& Noll, D. C. (1995). Improved assessment of significant activation in functional magnetic resonance imaging (fMRI): Use of a cluster-size threshold. Magnetic Resonance in Medicine, 33, 636-647.

Goebel, R., Esposito, F., \& Formisano, E. (2006). Analysis of functional image analysis contest (FIAC) data with Brainvoyager QX: From singlesubject to cortically aligned group general linear model analysis and self-organizing group independent component analysis. Human Brain Mapping, 27, 392-401.

Hale, T. S., Bookheimer, S., McGough, J. J., Phillips, J. M., \& McCracken, J. T. (2007). Atypical brain activation during simple and complex levels of processing in adult ADHD. Journal of Attention Disorders, 11, $125-140$.

Holroyd, C. B., Nieuwenhuis, S., Yeung, N., Nystrom, L., Mars, R. B., Coles, M. G., \& Cohen, J. D. (2004). Dorsal anterior cingulate cortex shows fMRI response to internal and external error signals. Nature Neuroscience, 7, 497-498.

Hurks, P. P., Hendriksen, J. G., Vles, J. S., Kalff, A. C., Feron, F. J., Kroes, M., ... Jolle, J. (2004). Verbal fluency over time as a measure of automatic and controlled processing in children with ADHD. Brain and Cognition, 55, 535-544.

Kaufman, A. S., \& Lichtenberger, E. O. (1999). Essentials of WAIS-III assessment. New York: Wiley.

Kooij, J. J. S., Boonstra, A. M., Swinkels, S. H., Bekker, E. M., De Noord, I., \& Buitelaar, J. K. (2008). Reliability, validity, and utility of instruments for self-report and informant report concerning symptoms of ADHD in adult patients. Journal of Attention Disorders, 11, 445-458.

Kray, J., \& Lindenberger, U. (2000). Adult age differences in task switching. Psychology and Aging, 15, 126-147.

Marchetta, N. D., Hurks, P. P., De Sonneville, L. M., Krabbendam, L., \& Jolles, J. (2008). Sustained and focused attention deficits in adult ADHD. Journal of Attention Disorders, 11, 664-676.

Marchetta, N. D., Hurks, P. P., Krabbendam, L., \& Jolles, J. (2008). Interference control, working memory, concept shifting, and verbal fluency in adults with attention-deficit/hyperactivity disorder (ADHD). Neuropsychology, 22, 74-84.

Monsell, S. (1996). Control of mental processes. In V. Bruce (Ed.), Unsolved mysteries of the mind: Tutorial essays in cognition (pp. 93 148). Oxford, England: Erlbaum (UK) Taylor \& Francis.

Murphy, P. (2002a). Cognitive functioning in adults with attention-deficit/ hyperactivity disorder. Journal of Attention Disorders, 5, 203-209.

Murphy, P. (2002b). Inhibitory control in adults with attention-deficit/ hyperactivity disorder. Journal of Attention Disorders, 6, 1-4.

Ossmann, J. M., \& Mulligan, N. W. (2003). Inhibition and attention deficit hyperactivity disorder in adults. The American Journal of Psychology, 116, 35-50.

Plichta, M. M., Vasic, N., Wolf, R. C., Lesch, K. P., Brummer, D., Jacob, C., .. . Grön, G. (2009). Neural hyporesponsiveness and hyperresponsiveness during immediate and delayed reward processing in adult attention-deficit/hyperactivity disorder. Biological Psychiatry, 65, 7-14.

Posner, M. I., \& Petersen, S. E. (1990). The attention system of the human brain. Annual Review of Neuroscience, 13, 25-42.

Raichle, M. E., MacLeod, A. M., Snyder, A. Z., Powers, W. J., Gusnard, D. A., \& Shulman, G. L. (2001). A default mode of brain function. Proceedings of the National Academy of Sciences, USA, 98, 676-682.

Raz, A. (2004). Anatomy of attentional networks. The Anatomical Record Part B: The New Anatomist, 281, 21-36.

Rogers, R. D., \& Monsell, S. (1995). Costs of a predictable switch between simple cognitive tasks. Journal of Experimental Psychology: General, 124, 207-231. 
Ruge, H., Brass, M., Koch, I., Rubin, O., Meiran, N., \& von Cramon, D. Y. (2005). Advance preparation and stimulus-induced interference in cued task switching: Further insights from BOLD fMRI. Neuropsychologia, 43, 340-355.

Rushworth, M. F., Hadland, K. A., Paus, T., \& Sipila, P. K. (2002). Role of the human medial frontal cortex in task switching: A combined fMRI and TMS study. Journal of Neurophysiology, 87, 2577-2592.

Schneider, M., Retz, W., Coogan, A., Thome, J., \& Rosler, M. (2006). Anatomical and functional brain imaging in adult attention-deficit/hyperactivity disorder (ADHD)—A neurological view. European Archives of Psychiatry and Clinical Neuroscience, 256(Suppl. 1), i32-i41.

Seidman, L. J. (2006). Neuropsychological functioning in people with ADHD across the lifespan. Clinical Psychology Review, 26, 466-485.

Seidman, L. J., Biederman, J., Weber, W., Hatch, M., \& Faraone, S. V. (1998). Neuropsychological function in adults with attention-deficit hyperactivity disorder. Biological Psychiatry, 44, 260-268.

Smith, A. B., Taylor, E., Brammer, M., Toone, B., \& Rubia, K. (2006). Task-specific hypoactivation in prefrontal and temporoparietal brain regions during motor inhibition and task switching in medication-naive children and adolescents with attention deficit hyperactivity disorder. The American Journal of Psychiatry, 163, 1044-1051.

Spencer, T. J., Biederman, J., \& Mick, E. (2007). Attention-deficit/hyperactivity disorder: Diagnosis, lifespan, comorbidities, and neurobiology. Journal of Pediatric Psychology, 32, 631-642.

Sunshine, J. L., Lewin, J. S., Wu, D. H., Miller, D. A., Findling, R. L., Manos, M. J., \& Schwartz, M. A. (1997). Functional MR to localize sustained visual attention activation in patients with attention deficit hyperactivity disorder: A pilot study. American Journal of Neuroradiology, 18, 633-637.

Talairach, J., \& Tournoux, P. (1988). Co-planar stereotaxic atlas of the human brain. New York: Thieme.
Tamm, L., Menon, V., Ringel, J., \& Reiss, A. L. (2004). Event-related fMRI evidence of frontotemporal involvement in aberrant response inhibition and task switching in attention-deficit/hyperactivity disorder. Journal of the American Academy of Child \& Adolescent Psychiatry, 43, $1430-1440$.

Tripp, G., \& Wickens, J. R. (2009). Neurobiology of ADHD. Neuropharmacology, 57, 579-589.

Uterwijk, J. (2000). WAIS-III Nederlandstalige bewerking. Technische handleiding [WAIS-III Dutch version. Technical manual]. Lisse, the Netherlands: Swets \& Zeitlinger.

Valera, E. M., Faraone, S. V., Biederman, J., Poldrack, R. A., \& Seidman, L. J. (2005). Functional neuroanatomy of working memory in adults with attention-deficit/hyperactivity disorder. Biological Psychiatry, 57, $439-447$.

Ward, M. F., Wender, P. H., \& Reimherr, F. W. (1993). The Wender Utah Rating Scale: An aid in the retrospective diagnosis of childhood attention deficit hyperactivity disorder. The American Journal of Psychiatry, 150, 885-890.

Weissman, D. H., Gopalakrishnan, A., Hazlett, C. J., \& Woldorff, M. G. (2005). Dorsal anterior cingulate cortex resolves conflict from distracting stimuli by boosting attention toward relevant events. Cerebral Cortex, 15, 229-237.

White, H. A., \& Shah, P. (2006). Training attention-switching ability in adults with ADHD. Journal of Attention Disorders, 10, 44-53.

Woods, S. P., Lovejoy, D. W., \& Ball, J. D. (2002). Neuropsychological characteristics of adults with ADHD: A comprehensive review of initial studies. Clinical Neuropsychology, 16, 12-34.

Received March 30, 2009

Revision received November 23, 2009

Accepted November 23, 2009

\section{E-Mail Notification of Your Latest Issue Online!}

Would you like to know when the next issue of your favorite APA journal will be available online? This service is now available to you. Sign up at http://notify.apa.org/ and you will be notified by e-mail when issues of interest to you become available! 